https://doi.org/10.37208/tgn27403

\section{Pugsley's marsh-orchid (Dactylorhiza traunsteinerioides) on the Mull of Kintyre, Argyll, Scotland}

\section{C.J. McInerny}

School of Life Sciences, University of Glasgow, Glasgow G12 8QQ

E-mail: chris.mcinerny @ glasgow.ac.uk

One of the rarest and most localised of the Dactylorhiza marsh-orchids in Britain and Ireland is the endemic Pugsley's marsh-orchid (D. traunsteinerioides) (BSBI, 2021; NBN, 2021). Its rarity, coupled with a fluctuating taxonomic status over the years, has resulted in the species acquiring an enigmatic and even legendary status (Pugsley, 1936; Allan \& Woods, 1993; Harrap \& Harrap, 2009; Stace, 2019; Cole \& Walker, 2020).

The species has been reclassified multiple times, reflecting the observation that it is a relatively newly formed taxon descended from multiple hybridisation events between common-spotted orchids (D. fuchsii) and early marsh-orchids (D. incarnata) (Cole \& Walker, 2020).

For a period Pugsley's marsh-orchid was given full specific status as D. traunsteinerioides, with those in north-west Scotland and some in the Republic of Ireland and Northern Ireland ascribed to the subspecies D. t. lapponica and named Lapland marsh-orchid (Harrap \& Harrap, 2009). However, later genetic studies indicated that it was instead a traunsteinerioides subspecies of the narrow-leaved marsh-orchid D. majalis, restricted to north-west Scotland, northern England, Wales, and the northern half of the island of Ireland (Hedrén et al., 2011). The same study also suggested that another subspecies - D. m. ebudensis found on North Uist, Outer Hebrides, Scotland - is genetically similar to D. m. traunsteinerioides, and that plants in southern England previously thought to be Pugsley's marsh-orchids are instead more closely related to another subspecies D. m. praetermissa.

Subsequent genetic analyses revised the taxonomy to indicate that plants in northern Scotland and possibly Northern Ireland were a subspecies - francis-drucei - of D. traunsteinerioides and named narrow-leaved marshorchid (Bateman \& Denholm, 2012; Stace, 2019). However, the most recent classification has reverted full circle to giving it full specific status again as D. traunsteinerioides and named Pugsley's marshorchid, with plants present in western Scotland, northern Wales, the Republic of Ireland, Northern Ireland and northern England, but those in south-east England of uncertain status (Cole \& Walker, 2020). This publication also concludes that the Hebridean marshorchid, at one time given full specific status as D. ebudensis, is a coastal ecotype of Pugsley's marshorchid.

I have visited a site on the Mull of Kintyre, Argyll three times over the past five years where a small population of Pugsley's marsh-orchid is present; the precise location is withheld for their protection. As relatively few photographs of $D$. traunsteinerioides from this area have been published and they are highly distinctive, a few images are reproduced with this Short Note (Figs. 1 and 2). Furthermore, some comments on their distinctive appearance, growth period and habitat requirements are provided. Combined, this information may allow interested observers to discover Pugsley's marshorchids in new areas in north-west Scotland; this seems possible as the taxon is likely under-recorded, being present in remote places, and is easily overlooked.

Pugsley's marsh-orchid has a strikingly early flowering period for an orchid in north-west Scotland, from midMay to mid-June, well before other Dactylorhiza orchids in the region. On my first visit to the site on 2nd July 2016 I could only find one plant whose flowering period was well "over". My second visit on 18th June 2017 revealed about ten orchids which had finished flowering, with just two still in flower that had been heavily shaded by surrounding tall grass (Fig. 1A-C).

The third visit on 4th June 2021 revealed around 15 spikes which were all in full flower (Fig. 2A-E). The spring of 2021 had an extended period of cool weather during May which may have delayed development of the plants, and so in a more typical year they may flower even earlier from mid-May. In early June 2021 very few other Dactylorhiza orchids were in flower at the site which holds common-spotted orchids, heath spottedorchids (D. maculata), early marsh-orchids and heathfragrant orchids (Gymnadenia borealis), which all flower later in the season. Hence, any "purple" orchid flowering during mid to late May in north-west Scotland should be carefully scrutinised.

At the site in Argyll the Pugsley's marsh-orchids grow at a location and habitat distinct from those of other Dactylorhiza orchids. They were on small south-westfacing slope ca. $5 \mathrm{~m}$ above a wet mire in an upland bog area at $230 \mathrm{~m}$ a.s.1. Few other Dactylorhiza orchids grow on the slope, but instead grow in large numbers on the mire below. However, later in the season, the same slope had a colony of heath fragrant-orchids. The slope is covered in grasses with much black bog-rush (Schoenus nigricans) present; black bog-rush is reported to be often associated with D. traunsteinerioides (Harrap \& Harrap, 2009; Cole \& Walker, 2020).

Pugsley's marsh-orchids are distinctive when compared with other Dactylorhiza orchids, with a combination of 


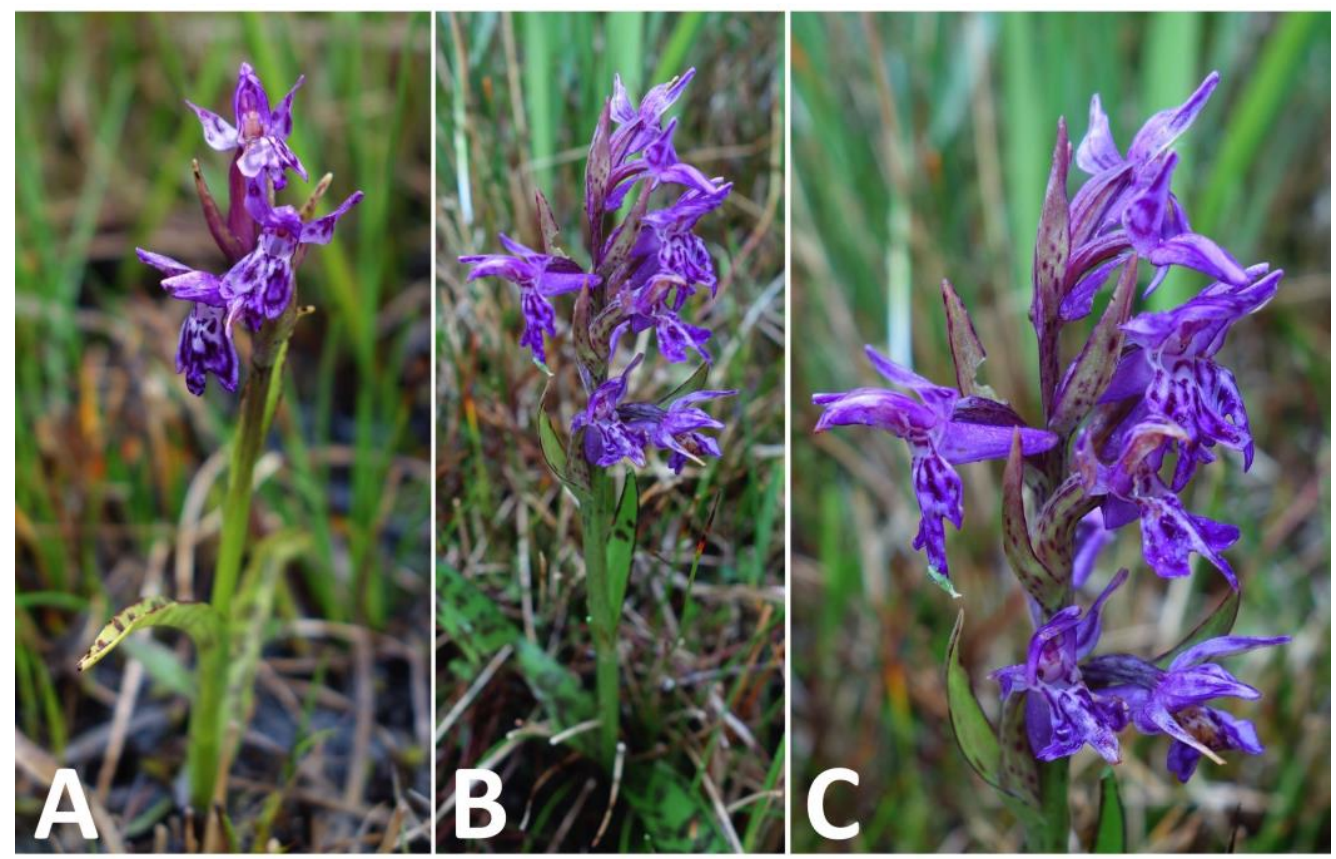

Fig. 1. Pugsley's marsh-orchid (Dactylorhiza traunsteinerioides), Mull of Kintyre, Argyll, Scotland, 18th June 2017. These photos show a number of features that identify this distinctive species, which are described in detail in the text. But note the small, lopsided flower head, heavily spotted leaves and complex deep purple lines on the flower lips and sepals. Note that (C) is an enlargement of (B) to reveal flower detail. (Photos: C.J. McInerny)
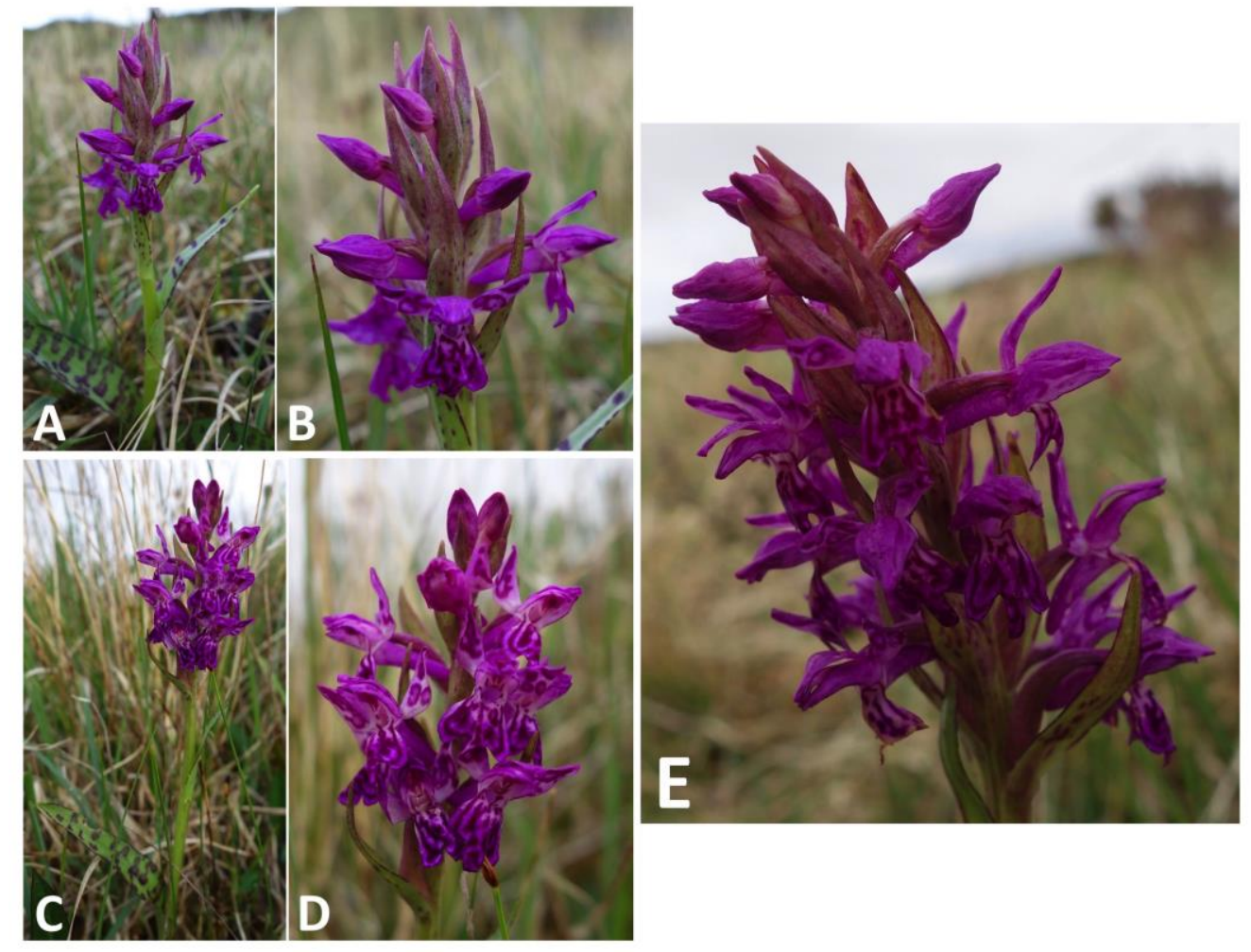

Fig. 2. Pugsley's marsh-orchid (Dactylorhiza traunsteinerioides), Mull of Kintyre, Argyll, Scotland, 4th June 2021. The flower spike shown in (E) is unusually large for the species but is still lopsided. The flowers in (A-D) are more typical in size and shape with the complex deep purple lines on the flower lips and sepal, and heavily marked leaves, evident in both. Note that (B,D) are enlargements of (A,C), respectively, to reveal flower detail. (Photos: C.J. McInerny)

features identifying the taxon (Harrap \& Harrap, 2009; Cole \& Walker, 2020) (Figs. 1 and 2). These include: (1) the bracts and upper stem are strikingly infused with purple; (2) the flowers are a vivid purple colour with complex darker purple markings of bold loops and blotches on the lips and lateral sepals; (3) the flower shape is typically three-lobed, with the central lobe longer and narrower than the two side lobes; (4) the flower head is often lopsided, with more flowers on one side than the other; (5) the flower head has relatively 
small numbers of flowers, typically 6-14, more rarely up to 18 ; (6) there are just three to five leaves evenly spaced on the stem, which are narrow, with the second leaf usually the widest being up $12 \mathrm{~mm}$ across; (7) sometimes, as illustrated in Figs. 1 and 2, the bracts and upper surface of the lower leaves are boldly marked with purple spots, the purple extending along the outer margin of the leaf. The presence or absence of purple spotting on the leaves and bracts was previously used in Scotland to separate the then recognised D. lapponica from D. traunsteineri (Allan \& Woods, 1993), but is now considered a variable character within D. traunsteinerioides (Cole \& Walker, 2020).

The extremely rare flecked early marsh-orchid, D. incarnata ssp. cruenta has been recorded from similar habitats to those occupied by D. traunsteinerioides in western Ireland and Scotland, but is found at just two sites in Scotland in Wester Ross (Allan \& Woods, 1993; Cole \& Walker, 2020). This subspecies of $D$. incarnata shares purple infusion on the bracts with $D$. traunsteinerioides, but has bold spots on both sides of the leaves. It also flowers later in the season, typically mid-June.

It is likely that the Pugsley's marsh-orchid is more widespread in north-west Scotland but is overlooked and under-recorded. Much apparently suitable moor habitat is present across the region where black bog-rush, often associated with $D$. traunsteinerioides, can be common and widespread. It is hoped that this Short Note has highlighted the features required to identify the taxon, and that observers will be vigilant to any purple Dactylorhiza orchids growing in the region that flower in mid- and late May, and examine them to see if they might be Pugsley's marsh-orchid.

\section{REFERENCES}

Allan, B. \& Woods, P. (1993). Wild Orchids of Scotland. (Edited by Gregory, N.M. \& Bates, M.). HMSO, Edinburgh.

Bateman, R.M. \& Denholm, I. (2012). Taxonomic reassessment of the British and Irish tetraploid marsh-orchids. New Journal of Botany 2(1), 37-55. https://doi.org/10.1179/2042349712Y.0000000004

Botanical Society of Britain and Ireland (BSBI) (2021). https://bsbi.org Accessed 6th June 2021.

Cole, S. \& Walker, M. (2020). Britain's Orchids: a Field Guide to the Orchids of Great Britain and Ireland. Botanical Society of Britain and Ireland, WildGuides \& Princeton University Press, Oxford. https://doi.org/10.1515/9780691206479

Harrap, A. \& Harrap, S. (2009). Orchids of Britain and Ireland: a Field and Site Guide. (2nd edition). A. \& C. Black, London.

Hedrén, M., Nordström, S. \& Bateman, R.M. (2011). Plastid and nuclear DNA marker data support the recognition of four tetraploid marsh orchids (Dactylorhiza majalis s.l., Orchidaceae) in Britain and Ireland, but require their recircumscription. Biological Journal of the Linnean Society 104, 107128.

https://doi.org/10.1111/j.1095-8312.2011.01708.x
National Biodiversity Network (NBN) Atlas (2021). http://www.nbnatlas.org Accessed 6th June 2021.

Pugsley, H.W. (1936). New British marsh orchids. Proceedings of the Linnean Society of London 148, 121-125. https://doi.org/10.1111/j.1095-8312.1936.tb00107.x

Stace, C. (2019). New Flora of the British Isles. (4th edition). C. \& M. Floristics. 